\title{
Unpowered Scooter-Related Injuries among Adolescents and Adults in the United States 2007-2017
}

\author{
Mercy Wakili Isichei', Alexander Femi Ale', Michael Ayedima Misauno', Pamela Brown², \\ Nicholas Dean Soulakis ${ }^{3}$ \\ ${ }^{1}$ Department of Surgery, Jos University Teaching Hospital, Plateau State, Nigeria \\ ${ }^{2} 727$ Tulane Drive, NE, Albuquerque, NM, USA \\ ${ }^{3}$ Division of Health and Biomedical Informatics, Department of Preventive Medicine, Northwestern University, Chicago, IL, USA \\ Email: mercyisichei@yahoo.com, MercyIsichei2019@u.northwestern.edu, falexale@yahoo.com, \\ micoyedim@yahoo.co.uk, salbpamb@yahoo.com,nicholas.soulakis@northwestern.edu
}

How to cite this paper: Isichei, M.W., Ale, A.F., Misauno, M.A., Brown, P. and Soulakis, N.D. (2020) Unpowered Scooter-Related Injuries among Adolescents and Adults in the United States 2007-2017. Open Journal of Emergency Medicine, 8, 13-20. https://doi.org/10.4236/ojem.2020.81002

Received: January 15, 2020

Accepted: February 29, 2020

Published: March 3, 2020

Copyright $\odot 2020$ by author(s) and Scientific Research Publishing Inc. This work is licensed under the Creative Commons Attribution International License (CC BY 4.0).

http://creativecommons.org/licenses/by/4.0/

\begin{abstract}
United States Consumer Product Safety Commission (CPSC) reported a 700\% increase in Emergency Department (ED) visits for injuries attributed to unpowered scooter use from January through October 2000. Our objective is to investigate injuries associated with the use of unpowered scooters among adolescents from the age of $>9$ years to $<20$ years and adults $>20$ years in the National Electronic Injury Surveillance Study (NEISS) data set from 2007-2017. We analyzed unpowered scooter-related injuries in the NEISS data set using variables: SCOOTER, INJURED, AFTER, OFF, AT and IN; the product code for injuries related to unpowered scooters is 1329 , and age $\geq 9$ years and $<99$ years using the Statistical Analysis System (SAS). Structured Query Language (SQL) was used to access database and to analyze frequencies and proportions. There were 7985 unpowered scooter-related injuries found in the NEISS data set over the study period. Gender distribution: Males 4330 (54.23\%), and Females 3655 (45.77\%). Age distribution: 6283 (78.69\%) >9 - $<20$ years, while $1702(21.31 \%)$ were $>19-<99$ years. Distribution by race: White 39.65\%, Not Specified (NS) 38.94\%, Black/African American 13.98\% and Others (Asian, American Indians, Alaskan natives, Native Hawaiians, and Pacific Islanders) $7.43 \%$. Body parts injured: head $16.19 \%$, followed by face $8.49 \%$, finger $8.30 \%$, lower trunk $8.30 \%$, ankle $5.60 \%$, upper trunk $5.35 \%$, internal injuries $0.99 \%$ and others $14.28 \%$. Most of the injuries were mild: Treated and Discharged 89.80\%, Hospitalized 7.68\%, and Death in ED 0.05\%. The locations of injuries were: Occurred at Home 43.47\%, UNK 29.78\%, Sports $12.63 \%$, Public $6.49 \%$, School $5.35 \%$, and Street $2.22 \%$. Injury trend: a
\end{abstract}


rise until 2010, a decline until 2015 and, then a sharp rise through 2017. Injuries from the use of unpowered scooters are a rising threat that should be given attention. Outcome: Most of the injuries $69.80 \%$ were mild treated and discharged, $7.68 \%$ were hospitalized, while death in ED was $0.05 \%$. Whereas: Transfer to referral hospital was about the same as in adults. Although most of these injuries were minor, head injuries could lead to more serious problems, and severe injuries could be life-threatening.

\section{Keywords}

Unpowered, Scooter, Injuries, Adolescents, Adults

\section{Introduction}

United States Consumer Product Safety Commission (CPSC) reported a 700\% increase in Emergency Department (ED) visits for injuries attributed to unpowered scooter use from January through October 2000 [1]. The number of people using unpowered scooters has increased in the years 2007 through 2017 (cite). It is a good recreational activity for both children and adults, and some found it a time-saving means of transport to work in heavy traffic [2] [3]. It's not surprising that it has become popular. Unpowered scooters, like cars, are used on streets and major roads although the regulatory requirements are not the same.

An estimated 27,600 persons sought ED care for scooter-related injuries from January through October 2000 [1]. CPSC reports show that peak injury periods that year occurred in the summer and fall, when there were in August, September, and October an estimated 6529, 8628 and 7359 injuries respectively requiring ED care [1]. Studies show that the body part most frequently involved is the head. Although most injuries were minor, there were injuries severe enough to require intensive care [4]. Others have reported serious injuries in children [5].

Despite the concerns about the dangers related to the use of unpowered scooters, there are no current studies evaluating the trend of unpowered scooter-related injuries in the United States.

Our objective is to investigate injuries associated with the use of push scooters among adolescents from the age of $>9$ years to $<20$ years and adults $>20$ years in the National Electronic Injury Surveillance Study (NEISS) data set from 2007 through 2017. To achieve this, we will estimate relative frequencies, annual incidence rates, types of injuries, body parts injured, severity of injuries and describe demographic features (gender and age) of those injured while using push scooters.

\section{Methods}

This is a retrospective study to analyze unpowered scooter-related injuries in the NEISS data from 2007-2017. The study population is adolescents and adults 
from the age of $>9$ years $-<99$ years who sustained unpowered scooter-related injury in the NEISS data set 2007-2017. NEISS variables used to extract data were: SCOOTER, INJURED, AFTER, OFF, AT and IN. The product code for injuries related to unpowered scooters is 1329 , and age $\geq 9$ years and $<99$ years was used to extract the data using the Statistical Analysis System (SAS).

Measurement used were: Age, gender, mechanism of injury, place of accident, and diagnoses. Injury in everybody region according to its relative severity on a six-point scale: (Minor, Moderate, Serious, Severe, Critical and Maximal (currently untreatable) was based on the Abbreviated Injury Scale (AIS). There are nine AIS chapters corresponding to nine body regions: Head, Face, Neck, Thorax, Abdomen, Spine, Upper Extremity, Lower Extremity, External and Other. In the NEISS data set imported into SAS, the product code and age were extracted frequencies for incidence. We used the product code 1329, body part, location and disposition in the NEISS data set to obtain body parts injured, where accident occurred and the treatment outcome. HPSPLIT was used for baseline, narrative and signals to obtain the timelines and possible outbreaks. Structured Query Language (SQL) was used to access database and to analyze frequencies and proportions. Data summary was done using graph and charts for key indicators. The main outcomes of interest are the frequency of injury, annual incidence rates, types of injuries, body parts injured, severity of injuries as described by disposition and demographic features (gender and age) of injuries in the study group.

\section{Results}

There were 7985 unpowered scooter-related injuries found in the NEISS data set over the study period. Gender distribution: Males 4330 (54.23\%), and Females $3655(45.77 \%)$. The age distribution was $6283(78.69 \%)>9-<20$ years, while 1702 (21.31\%) were $>19$ - <99 years. The distribution by race was: White $39.65 \%$, Not Specified (NS) 38.94\%, Black/African American 13.98\% and Others (Asian, American Indians, Alaskan natives, Native Hawaiians, and Pacific Islanders) $7.43 \%$. The distribution of body parts injured was: head $16.19 \%$, followed by face $8.49 \%$, finger $8.30 \%$, lower trunk $8.30 \%$, ankle $5.60 \%$, upper trunk $5.35 \%$, internal injuries $0.99 \%$ and others $14.28 \%$ (see Figure 1).

The locations of injuries were: Occurred at Home 43.47\%, UNK 29.78\%, Sports 12.63\%, Public 6.49\%, School 5.35\%, and Street 2.22\% (see Figure 2). The trend of injuries showed a steady increase from 2006 to a peak in 2010, then, a steady decline in 2015 and another sharp increase in 2017 (see Graph 1). The most common type of injuries sustained among adolescents were fracture 2138 (34.03\%), contusion/abrasion 1321 (21.03) and strains/sprains 944 (15.03), while in adults the most common injuries sustained were contusion/abrasions 419 (24.62), fracture 376 (22.09) and strains/sprains 301 (17.68) (see Figure 3). Outcome: Most of the injuries $69.80 \%$ were Mild treated and discharged, $7.68 \%$ were hospitalized, while Death in ED was $0.05 \%$. Whereas: Transfer to referral hospital was about the same as in adults. 
Frequency (percentages ) Body part injured: unpowered scooter injuries USA, NEISS 2007-2017

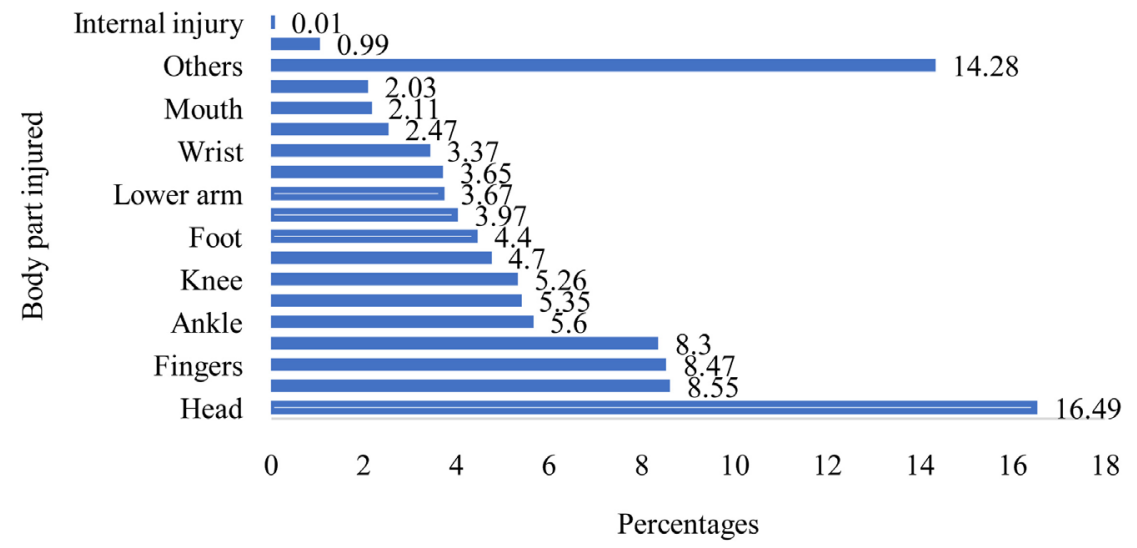

Figure 1. Unpowered scooter related injury per body part injured among adolescents $>9$ $<20$ years and adults $>19$ years, NEISS 2007-2017.

\section{Location of unpowered scooter injuries}
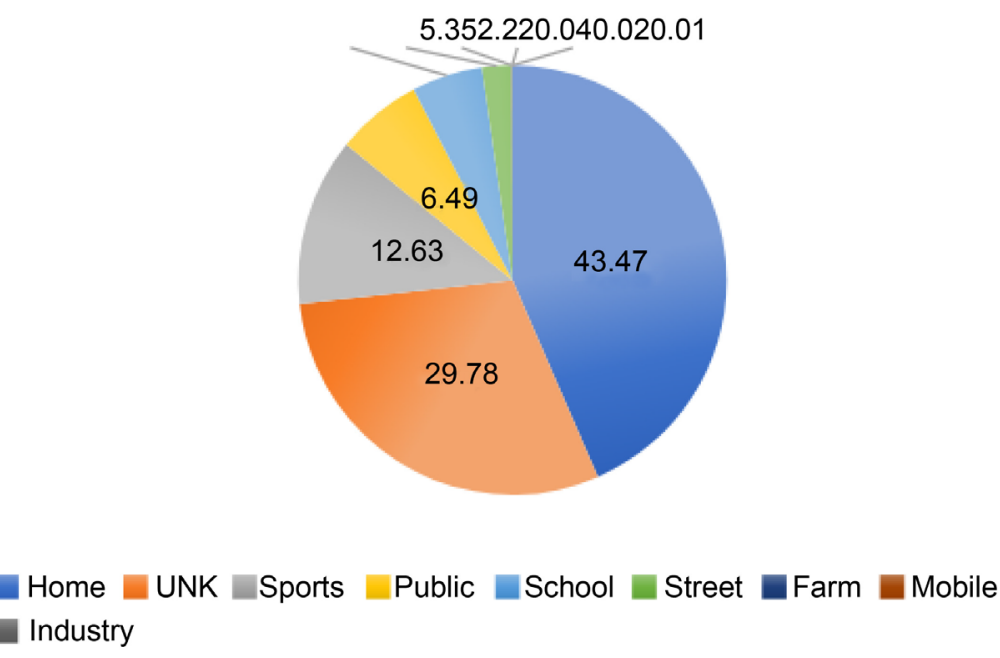

Figure 2. Location of unpowered scooter injuries in adolescents $>9-<20$ years and adults $>19$ years in the US from 2007-2017.

\section{Discussion}

The findings in this study show that there is an overall increase in unpowered scooter-related injuries from 2007-2017 in the United States. They however show a trend of steady increase, then a decline, and a recent upward trend. The upward trends could be attributed to the release of newer unpowered scooter models, which attract more users [1] [6]. Other reasons for the trends could be increased awareness of regulations, such as a requirement for helmet use. Such a requirement could lead to a decrease in injuries for a period of time, with the rule later disregarded. Rules vary wildly among states. A report of a study done to investigate reasons for increased ED visits among children in the United States showed that injuries were mainly related to the use of unpowered scooters [8]. 
Unpowered scooter injuries among adolesent $>9-<20$ years and adult $>20$ years in the US, NEISS data $2007-2017$

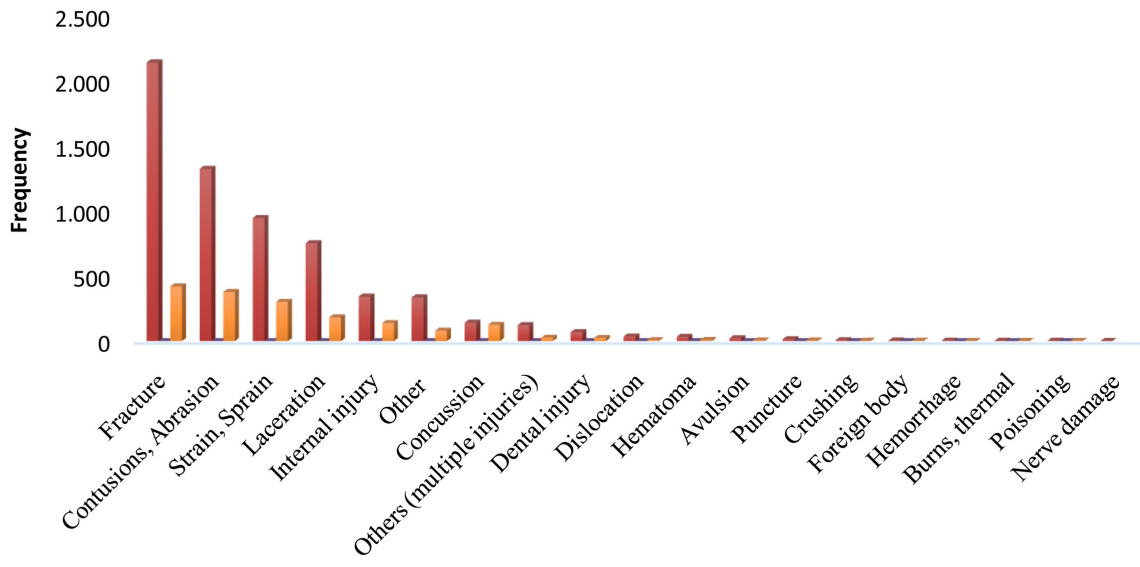

Injury type

- Adolescents adult

Figure 3. Differences in incidence of unpowered scooter related injury between adolescents $>9-<20$ years and adults $>20$ years in the US, 2007-2017.

Injury per year 2007-2017

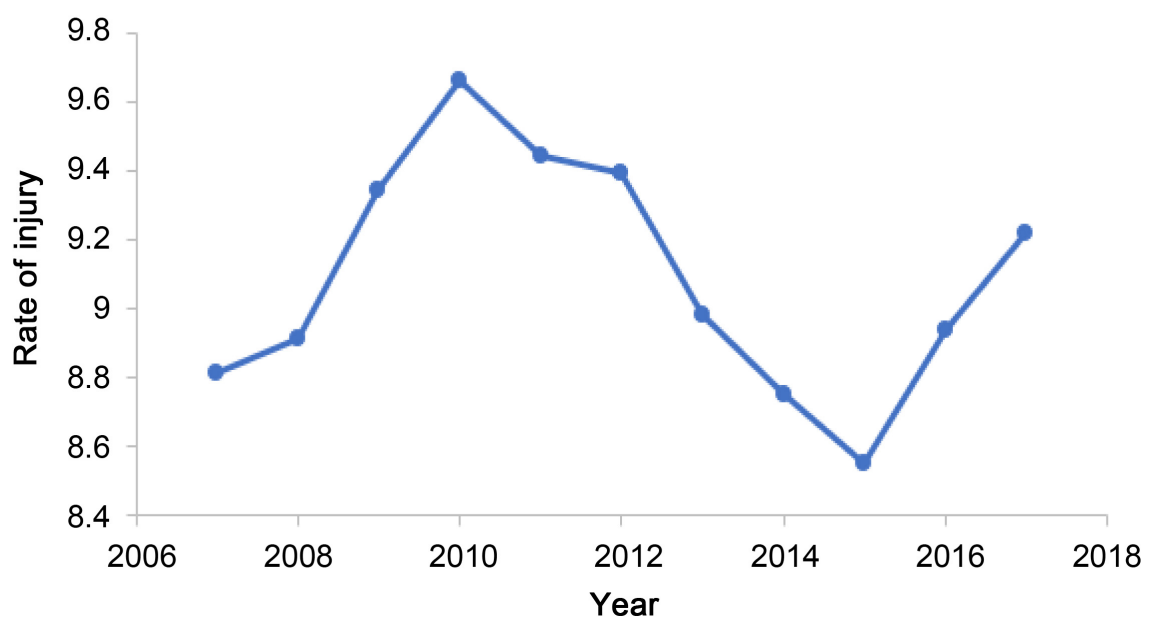

Graph 1. Unpowered scooter injury among adolescents $>9-<20$ years and adults $>19$ years per year 2007-2017 in the US, NEISS data.

\section{Severity of Injuries}

The majority of the injuries was minor, but those injuries that required hospitalization were severe. The body part most frequently traumatized was the head. Repeated trauma to the head could result in severe head injury. There are reports of severe head injuries sustained while riding unpowered scooters that resulted in permanent brain damage [7] [8]. Helmet use has been reported by the CPSC to reduce the risk of head injury by $80 \%$ [2]. Studies however show that the majority of small-wheeled users do not use a helmet [7] [8]. A study among push scooter users in Switzerland showed that the majority does not use helmet [9]. 
In this study there were various range of internal injuries requiring hospitalization or referral and there was death in the ED. Internal injuries that included severe damage to face, dental injuries, and tracheal injuries sustained through accidents related to unpowered scooters use have been reported although there was no death [10]. A study done in Finland also reported that the majority of their study subjects (69\%) sustained fractures, while $26 \%$ had injuries that required anesthesia and surgical intervention [11] [12] [13].

In our study we found more males used unpowered scooters than females and more adolescents than adults. The reason could be that the adolescents use them as a recreational activity and with less caution. Unpowered scooter riding has been reported to be a form of recreation in children and adolescents, but the incidence of injuries has steadily increased even with the introduction of newer versions of scooters [14].

\section{Limitations}

1) The NEISS data are collected from various EDs all over the United States. There might be some slight differences in terms used for coding. This study used only terms described in the methods section, therefore, there might be some missing data as a result of misclassifications.

2) We analyzed unpowered scooter injuries only, not powered scooter injuries. The two could be analyzed separately or compared for injury severity.

3) Rules vary wildly among states for small-wheeled users.

\section{Conclusion}

Injuries from the use of unpowered scooters are a rising threat that should be given attention. Although many of these injuries are minor, head injuries could lead to more serious problems, and severe injuries could be life-threatening or even fatal. Instituting early preventive measures could reduce injuries related to the use of these products.

\section{Acknowledgements}

Institute for Global Health, Northwestern University D43 Fogarty NIH grant sponsored this training as part of my output for master degree in Clinical Investigation at Northwestern University Chicago, IL. Sally Barlow, Albuquerque, New Mexico, USA, helped proofread this article.

\section{Conflicts of Interest}

The authors declare no conflicts of interest regarding the publication of this paper.

\section{References}

[1] (2001) Unpowered Scooter-Related Injuries-United States, 1998-2000. JAMA, 285, 36-37. https://doi.org/10.1001/jama.285.1.36 
[2] Consumer Product Safety Commission (2000) National Electronic Injury Surveillance System [computer file]. Consumer Product Safety Commission, Washington $\mathrm{DC}$

[3] Kubiak, R. and Slongo, T. (2003) Unpowered Scooter Injuries in Children. Acta Paediatrica, 92, 50-54. https://doi.org/10.1111/j.1651-2227.2003.tb00468.x

[4] Majercik, S., Day, S. and Stevens, M.H. (2015) Epidemiology of Traumatic Brain Injury after Small-Wheeled Vehicle Trauma in Utah. Neurosurgery, 77, 927-930. https://doi.org/10.1227/NEU.0000000000000957

[5] Schalamon, J., Sarkola, T. and Nietosvaara, Y. (2003) Injuries in Children Associated with the Use of Nonmotorized Scooters. Journal of Pediatric Surgery, 38, 1612-1615. https://doi.org/10.1016/S0022-3468(03)00571-2

[6] Miggins, M., Lottenberg, L., Liu, H., Moldawer, L., Efron, P. and Ang, D. (2011) Mopeds and Scooters: Crash Outcomes in a High Traffic State. The Journal of Trauma, 71, 217-222. https://doi.org/10.1097/TA.0b013e318208f874

[7] Daverio, M., Babl, F.E., Barker, R., Gregori, D., Da Dalt, L. and Bressan, S., Paediatric Research in Emergency Department International Collaborative (PREDICT) Group (2018) Helmet Use in Preventing Acute Concussive Symptoms in Recreational Vehicle Related head Trauma. Brain Injury, 32, 335-341. https://doi.org/10.1080/02699052.2018.1426107

[8] Ong, J.S., Soundappan, S.V., Adams, S. and Adams, S.J. (2018) Helmet Use in Bicycles and Non-Motorized Wheeled Recreational Vehicles in Children. Paediatrics \& Child Health, 54, 968-974. https://doi.org/10.1111/jpc.13925

[9] Mebert, R.V., Klukowska-Roetzler, J., Ziegenhorn, S. and Exadaktylos, A.K. (2018) Push Scooter-Related Injuries in Adults: An Underestimated Threat? Two Decades Analysed by an Emergency Department in the Capital of Switzerland. BMJ Open Sport \& Exercise Medicine, 4, e000428. https://doi.org/10.1136/bmjsem-2018-000428

[10] Eipe, N. and Choudhrie, A. (2007) Tracheal Rupture in a Child with Blunt Chest Injury. Pediatric Anesthesia, 17, 273-277. https://doi.org/10.1111/j.1460-9592.2006.02076.x

[11] Wallace, A., Rogers, H.J., Zaitoun, H., Rodd, H.D., Gilchrist, F. and Marshman, Z. (2016) Traumatic Dental Injury Research: On Children or with Children? Dental Traumatology, 33, 153-159. https://doi.org/10.1111/edt.12299

[12] Ho, C., Coimbra, R. and Hoyt, D.B. (2001) Severe Traumatic Brain Injury from Unmotorized Scooter. Journal of Emergency Medicine, 21, 133-136. https://doi.org/10.1016/S0736-4679(01)00356-0

[13] Myles, B.A., Scott, A.H., Dao, M.N. and Dana, L.W. (2001) Scooter Injuries: A New Pediatric Morbidity. Pediatrics, 108, E2. https://doi.org/10.1542/peds.108.1.e2

[14] Beck, S., Barker, L., Chan, A. and Stanbridge, S. (2020) Emergency Department Impact Following the Introduction of an Electric Scooter Sharing Service. Emergency Medicine Australasia. https://doi.org/10.1111/1742-6723.13419 


\section{Appendix}

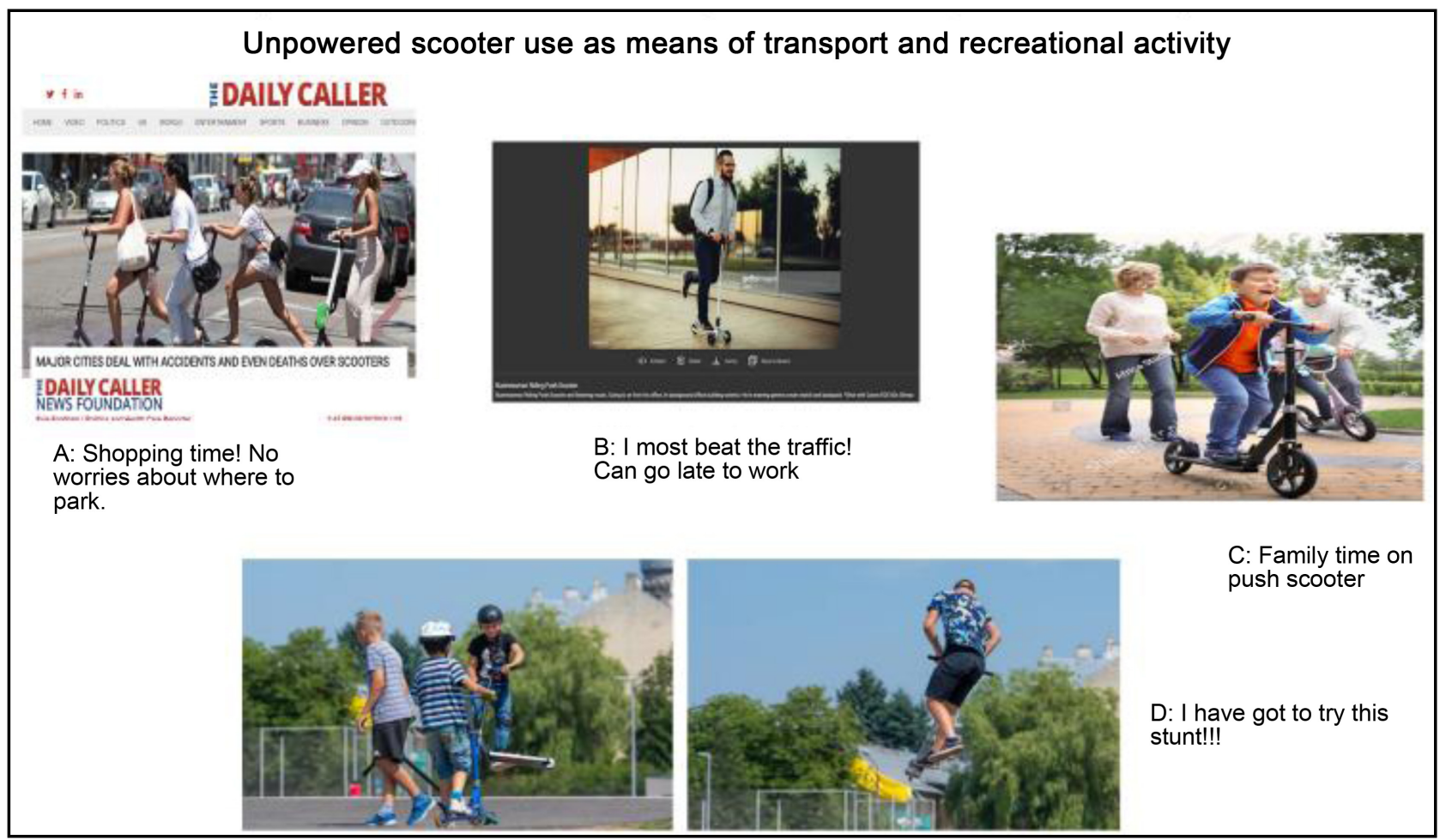

Source: From the internet. 